Article

\title{
Young Patients' Views on the Open Web 2.0 Childhood Diabetes Patient Portal: A Qualitative Study
}

\section{Sam Nordfeldt ${ }^{1,2,3, *}$ and Carina Berterö ${ }^{4}$}

1 Center for Medical Technology Assessment, Department of Medicine and Health Sciences, Linköping University, S-58185 Linköping, Sweden

2 Division of Child and Adolescent Psychiatry, Department of Clinical and Experimental Medicine, Linköping University, S-58185 Linköping, Sweden

3 Division of Pediatrics, Department of Clinical and Experimental Medicine, Linköping University, S-58185 Linköping, Sweden

4 Division of Nursing Science, Department of Medical and Health Sciences, Linköping University, S-58185 Linköping, Sweden; E-Mail: carina.bertero@liu.se

* Author to whom correspondence should be addressed; E-Mail: sam.nordfeldt@lio.se.

Received: 11 April 2012; in revised form: 3 May 2012 / Accepted: 9 May 2012 /

Published: 18 May 2012

Abstract: Little is known about the views of young patients themselves on interactive Web portal services provided by pediatric practitioners. We aimed to explore their perceptions of a real-world diabetes portal that offers facts and contact with peers and practitioners; e.g., discussion forums, blog tools, self-care and treatment information, research updates and news from local practitioners. Twelve young patients (ages 12-21, median 15 years), one boyfriend, 7 mothers and one father each wrote an essay on their experience from use of the portal. Their essays underwent qualitative content analysis. A major theme was "Helping and facilitating daily life with diabetes”, the portal was perceived as a place where contents are interesting, inspiring and may trigger users' curiosity. There were three subthemes; "Ease of use in my everyday life," which includes the perception that the portal was perceived as smooth and easy to enter and navigate whenever needed; that information was easy to understand for different groups of users. "Support via an exchange of experience," includes the ability to contact peers being regarded advantageous. Some said that just reading others' experiences can be helpful in terms of persevering; children could find peers in the same age group. "Evidence based information," includes the perception of the portal being a useful and trustworthy source of facts on e.g., physical activity, blood glucose, medical devices, emotional wellbeing, food and nutrition, and other aspects that impact living with 
diabetes. Young users expressed positive perceptions towards the interactive web portal. Such services seem to have great potential for supporting young patients and significant others - intergrading for confidence.

Keywords: Web 2.0; eHealth; type 1 diabetes; self-care; disease management; patient information; learning; intergradation; health care professionals; children; adolescents; parents

\section{Introduction}

Internet use today is increasingly enabling patients to manage their everyday care supported by interactive components. The accumulated daily experiences of patients and parents form a knowledge base from which information can be shared with others [1,2]. Complementary to traditional authorities, new online resources, including peer contacts, may offer trustworthy information or add credibility to information [1]. Young people with long-term health problems like the concept of one site tailored to answer their questions; active forum discussion boards and chat rooms are perceived as attractions of great value [3-5]. Parents may inform other parents regarding a wide range of issues, as can adolescents and children, on their own level, based on their maturity and autonomy. Online communities have been used for a decade or more [2,6,7], and users include young people living with diabetes [4]. Recent research demonstrates how online support groups may contribute to patient empowerment [8].

Health professionals need to tailor services for adolescents with long-term health problems appropriately [3,9].

Access to updated patient information from practitioners might enhance the evolution of empowered patients; thus electronic communication is promising for diabetes care [10,11]. However, in a recent review, it was found that technology-based interventions rarely support patient-practitioner collaboration aimed at a better balance between self-care and professional care [12]. Few studies have focused on young users' perspectives; i.e., patients relating experiences in their own words, and much remains to be learned [13-15]. In a recent survey from Sweden among 12-15 year-olds, 91\% have already been searching online for answers to questions on health issues [16]. We have found few information systems in routine use in pediatric diabetes care that have been developed and evaluated in collaboration with children and their families [17-20].

Management of childhood type 1 diabetes requires daily intensive self-treatment, including numerous daily decisions regarding adaptation of treatment to the current life scenario [21,22]. Variation of the disease over time, along with the disease trajectory and the course of individual development, require attention and support for self-care in a long-term perspective $[10,21,23]$. In patients' and parents' perspective on quality of care, improvements are needed regarding information and access to services [23]. Young patients, their families and significant others perceive a wide range of information and support needs which can be well understood and verified from a clinical perspective [3,21-25].

The umbrella terms Web 2.0, Health 2.0 and Medicine 2.0 mirror a development area with a range of collaborative Internet applications facilitating user participation and co-creation of online health information [1]. 
Perception means the knowledge gained from a process of coming to know or understand something, implying the ability to understand inner qualities and relationships. Previously we have explored the perceptions of practitioners and families involved in a trial with a diabetes Web 2.0 portal, but only in a password-protected setting and data were obtained mainly from adults [3,25]. Thus little has been known about the views of children and adolescents themselves on such resources provided openly on the Internet.

\subsection{Aims}

The aim of this study was to explore young patients' perceptions of a tailored open Web portal, combining factual information with interactive components and user-generated contents to support self-care. Opportunities and obstacles related to the implementation in clinical practice were sought.

\subsection{Structure of Care}

In Sweden, children and adolescents with diabetes are treated by hospital-based pediatric diabetes teams, consisting of nurses and nurse specialists, physicians and dieticians, social workers and/or clinical psychologists. The practitioners meet the young patients, along with their parents, when hospitalized at onset, and continue to see them quarterly, or more often, as outpatients over many years. The process of care, the treatment policy and perceived quality of care have been described elsewhere $[22,23,26]$.

\subsection{Web Portal}

During 2006-2008 the use of a Web diabetes portal for invited patients and parents was studied; a personal password was required [3,27]. The portal had been developed from a design model and a prototype [28]. The design process had included iterative sessions over a long period of time with groups of patients, parents and practitioners; thus it was designed for use by these groups and their significant others. A predominant finding from the studies had been the gatekeeper function of password requirements [3,27]. Thus a largely open portal was suggested to enhance use by those associated with the child with diabetes. After design developments based on previous studies, the open Web portal was launched on World Diabetes Day, November 14, 2008.

The objective of the portal was to complement traditional treatment by enhancing diabetes-related information and communication supportive for the target group. As previously described, the portal combined extensive general as well as local information along with patient- and guardian-mediated information and dialogues [3]. Thus the portal offered open discussion forums (Figure 1), blog tools and blogs related to diabetes, self-care and treatment information from practitioners (Figure 2), diabetes newsfeeds, including research updates with comments, interactive pedagogic devices such as an online diabetes simulator, and more. The portal also provided contact information and news from local practitioners, medical prescription renewal, appointment and question services, photo presentations of staff, and locally-produced general information using a personal tone “...what I may say to a newly diagnosed child and parents”. The practitioners' information was based on scientific evidence and best clinical practice, and aimed at creating a trustworthy and reliable source of information. For the community areas, there was a set of rules for use, based on common sense and national laws, with 
individual users responsible for the information provided. Practitioners observed the dialogues in the discussion forums.

Figure 1. A sample of practitioner information entitled "I made a mistake with the insulin!” with advice for specific emergencies. The text at the bottom of the screen includes “Written by...”, "Revised by...” (names, affiliations).

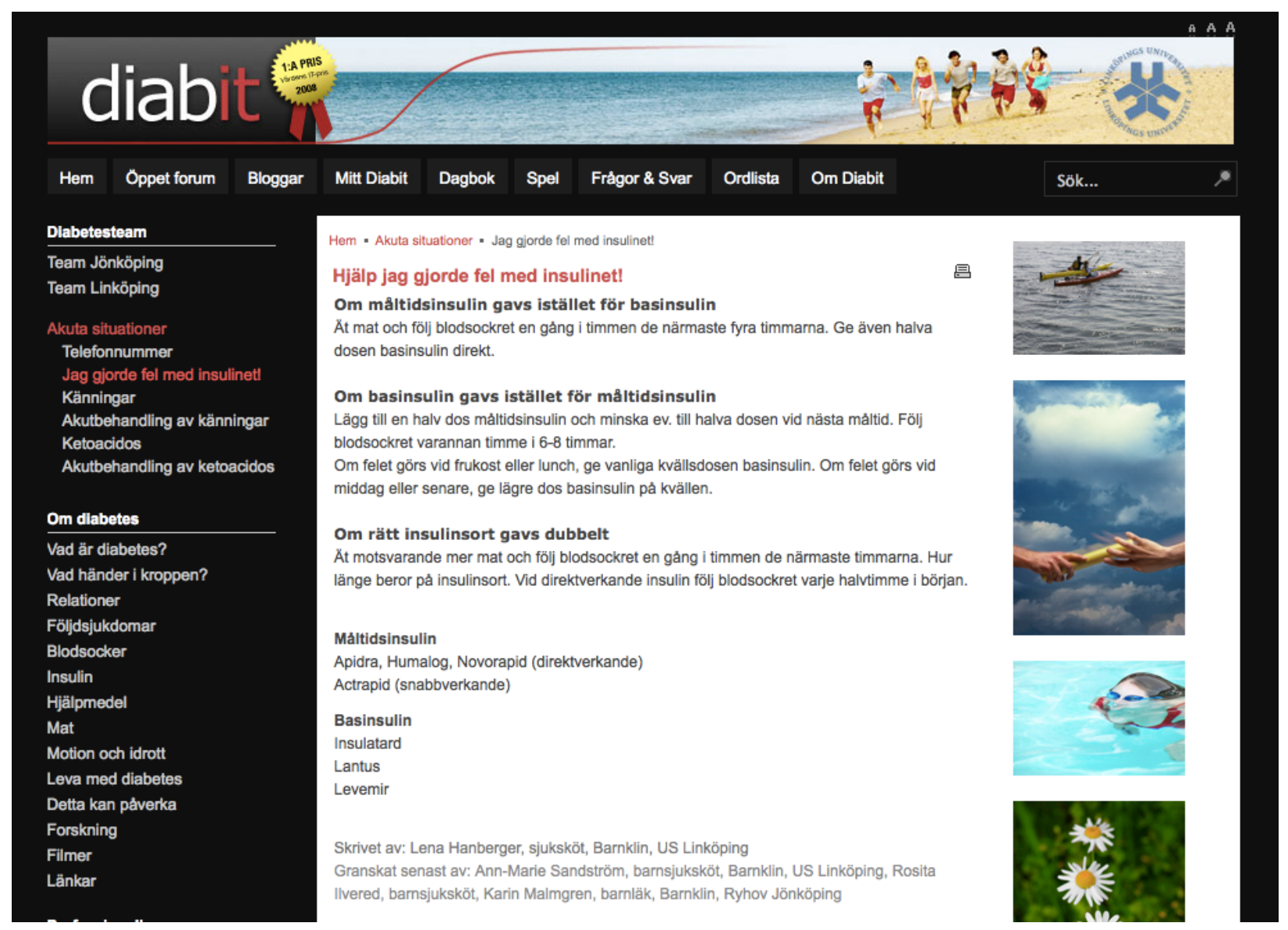

\subsection{Study Population and Data Collection}

The participants were pediatric patients, and their parents, treated by diabetes teams at pediatric clinics in south-eastern Sweden. Letters were sent in 2009 to geographic populations of two clinics with approximately 200 and 250 patients, respectively, below the age of 19 years. The invitation was also presented on the open portal without geographical restrictions. Patients aged 12-18 years and mothers and fathers of all children were invited. They could respond by e-mail or by mail to an independent researcher who was not their practitioner.

Of the 21 responders (17 females, 4 males), 7 were mothers (ages 37-49 years), 1 was a father, 1 was a boyfriend (age 17 years) of a young patient, and 12 were young patients (ages 12-21 years, median 15 years). All responders reported some experience with using the portal. 
Figure 2. A sample discussion forum dialogue.

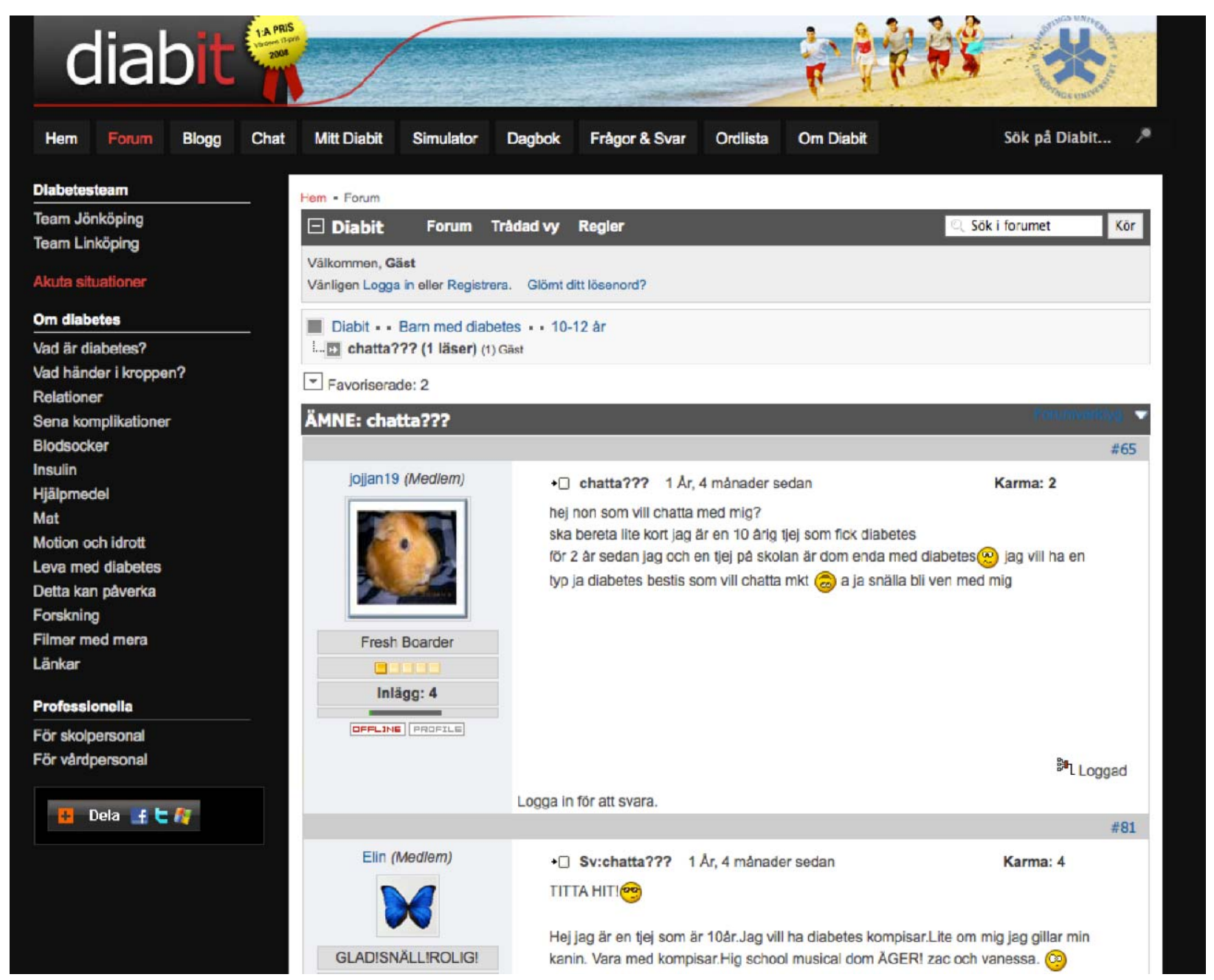

The respondents were asked to write an essay about their positive as well as their negative experiences with using the open portal in 2009, irrespective of frequency and/or success in doing so. The decision to use essays was related to the fact that young Internet users frequently write their comments and opinions. Two leading questions were asked, followed by some clarifying questions:

"Tell me about a situation when you succeeded in using the portal. Has the portal made managing the disease easier in any way? Are there any advantages in using the portal?

Tell me about a situation when you did not succeed in using the portal. Has the portal become an obstacle in some way? Are there any disadvantages in using the portal?”

\subsection{Data Analysis}

Considering the exploratory aim of the study, the respondents' essays were analyzed as a whole using modern techniques of conventional qualitative content analysis [29]. Qualitative content analysis can be applied, for example, to transcribed interviews, texts, narratives, letters, documents, protocols and media [30]. 
As the text material was read, statements with similarities were clustered and summarized into tentative positive and negative themes based on the questions used. The tentative themes with all respective statements were reviewed in detail. Unclear statements were explored with respect to the original context.

Through iterative in-depth discussions with stepwise re-categorizations and repeated validations vs. the complete primary data, a logical and complete structure gradually emerged. In a later and final stage of validation, the complete sentences from the original text material were again reviewed in their original context and condensed into final themes, including some final adjustments.

Thus all the themes were validated through systematic reviews of the material. To confirm and illustrate the themes and subthemes selected, quotations related to the respective themes were considered throughout the work process. The quotes used in the results section were chosen to illustrate themes emerging from all the respondents' statements.

The above analysis was performed by both authors. Before the sessions both of them read all the primary data and the material emerging in the analysis. Initially, the essays were analyzed by each of the authors independently, and open comparisons were made iteratively. Any discrepancies were resolved through discussion; no measure of reliability between the raters was used.

The co-author was experienced in the methods used for data collection and analysis as well as in nursing and nursing research. The main author was experienced in clinical research and the care of the target group and he was also familiar with the elements and design of the system. The risk for bias due to the authors' preconceptions or potential expectations was prevented as far as possible through the repeated validations vs. the primary data and the in-depth supervision sessions.

\subsection{Ethics Statement}

The study was approved by the Research Ethics Committee of the Faculty of Health Sciences at Linköping University, Linköping, Sweden, in accordance with the Declaration of Helsinki. Data were analyzed anonymously.

\section{Results and Discussion}

\subsection{Helping and Facilitating Daily Life with Diabetes}

A major theme was that the portal was perceived as a tool that helps those who live daily with diabetes, a nice, pleasant place to be where the contents are interesting. Using it was inspiring in various ways, and it could also trigger users' curiosity. Users felt they got answers and found the information they needed, and they said it had excellent information about diabetes. Exchanging experiences and

having contacts with others through the portal was seen as valuable and a source of self-confidence, as was being able to find facts and correct information.

If you have a question, all you have to do is log onto the site and see if you find the answer, or you can also ask another user or someone on the diabetes team.

The basis for this was that the portal was perceived as user-friendly with a nice atmosphere that was easy to access. Some respondents visited the site occasionally because they were curious, while others 
used it regularly as a place to find various tips and advice. There are many things to find: various snacks, breakfast cereals, new recipes for meals and baked goods, or using a virtual blood glucose diary, or an online simulator - some good stuff for different situations.

This major theme was built upon the following three subthemes.

\subsection{Ease of Use in My Everyday Life}

Entering the portal whenever needed, from a computer anywhere, was perceived as smooth and easy. Some users appreciated found that information found quickly on the portal took less time than waiting on the telephone, and the current, largely open site worked better as compared to the previous version with a password requirement. The portal as a whole was perceived as well designed, easy to understand, and functional for users. It was easy to find their way around on the site, and the information was also easy to read and easy to understand. It was perceived as easy to search and find specific information concerning various aspects of diabetes. Being enabled to quickly find answers that were needed was regarded as advantageous. Some users commented that they had never had failures when using the portal. Some suggested an e-mail reminder service so that they would not forget to visit the site.

[name of portal] works really well for me and I've got a lot of tips and advice from the site

It was appreciated that the site targeted different groups of users, such as parents, adolescents, younger children, and significant others, including school professionals, relatives, friends and important people in other activities, such as sport coaches,.

You can find just about everything imaginable and in addition it is aimed at parents, parents of small children, and young people, and that's really good

Only a few perceived problems were identified for users themselves. One user alerted the staff about an incorrect phone number and that was then corrected, and someone else commented on a missing phone number in the contact information. For the community functions, a clearer design was suggested to make it easier to become a member.

\subsection{Support via an Exchange of Experiences}

Many users reported that being able to talk to others with diabetes was a great advantage of the portal.

I'm happy with [name of portal], the site is easy to understand and you can get a lot of tips and ideas, the forum part is fantastic

Reading the messages in the open discussion forum was considered interesting because users could learn things from others with diabetes who were in the same situation. Some said this was a real comfort to them. It was expressed that simply reading about the experiences of others, both positive and negative, could help them carry on. In addition to getting answers about things they wondered about, they could also help others who were unsure about things. For example, some said that right after the onset of diabetes, it could be good to get advice from those who were more experienced. Some mentioned that it was of value to find peers in the same age group who knew what it was all 
about (living with diabetes at that age). Furthermore, children could see that others also had diabetes, and the fact that children could also find peers with diabetes was appreciated.

I logged onto [name of portal] and checked, and there were a huge number who'd written that they wanted to have someone to, like, talk to. And all I had to do was answer them so it's really good. It's so hard to find people my own age who also have diabetes...

Regarding further development of the service, some users felt it would be fun to be able to talk with peers worldwide as well in the forums, and a chat function was also suggested.

With respect to the open discussion forum and blogs, some older adolescents as well as some parents felt less interested since they perceived that few users in their respective age groups were active. Some users said that the site seemed to be unknown and that the discussion forums had not really got started, as it sometimes could take a long time to get a reply. This was considered just a matter of time, so that when more members gradually joined in, the community would become more active.

One individual perceived that the site seemed too serious and hospital-like and was therefore not willing to use the discussion forum, even though many potential advantages were expressed as well.

\subsection{Evidence-Based Information}

Many appreciated the portal as a useful and apparently trustworthy source of facts that was providing much good information regarding diabetes in daily life. They found it advantageous in that their questions had been answered and it had been easy to find and read the desired information. Individual users mentioned that not everything on the Internet can be trusted.

I've found answers to my questions many times when I've searched on [name of portal], and especially when my daughter didn't feel mentally well.

A number of examples were given showing specific information needs that had been met, for example concerning physical activity and blood glucose, available medical devices, emotional wellbeing and diabetes, food and nutrition, and other factors with an impact on life with diabetes.

One of the many times I used [name of portal] was when I read about how exercise affects blood sugar and insulin dosing, I found what I needed and I think there are really good things about diabetes and a lot of good tips and advice

A young user commented; It could also be interesting just to see what's there - that is, without searching for specifics. Moreover, some had used the information not only for themselves but also for schoolwork and other writing tasks.

An individual user said that she used to visit the site when searching for news and updates in the field, but once having read most of the extensive general information there were few reasons to look at it again.

Regarding suggestions for improvement, some indicated specific needs, such as a section for those with both diabetes and celiac disease. 


\section{Conclusions}

On the whole, the informants regarded the portal as helpful and as facilitating daily life. They expressed a sense of its usefulness in everyday life with diabetes that was associated with things such as getting new inspiration, a good spirit and that it evoked curiosity. Patients and their parents valued being able to search for specific information when needed, which can be well understood and verified from a clinical perspective $[21,23,25]$. This, as well as earlier studies, suggests that enhanced online access to information might contribute to improvements in coping with the disease and being more in control $[3,8,10,12]$. Thus, questions arise as to what the key elements might be that generate this sense of usefulness.

Empowering processes identified among adult users of online support groups include exchanging information, encountering emotional support, finding recognition, sharing experiences, helping others, and amusement $[8,31]$. Based on the present study, a totality of functions easy to use and resources for all involved seems important. Many comments indicated a perception of friendliness and/or helpfulness derived from a variety of aspects in the functions and design. Some users said it was easy to find their way around, easy to understand the site, easy to read and to understand its contents. Some mentioned they had not experienced any failures in using the site, and some were satisfied that reported errors had been corrected promptly. Many indicated positive personal experiences of finding helpful information or from an exchange of experiences.

If a sense of helping and facilitating is achieved, an online resource presumably will be more likely to attract returning visitors [32]. Health care professionals and system developers should be alert to this advantage and make use of it in designing such resources as close as possible to users' needs in order to decrease attrition [33,34]. Some online medical information services were found to be hampered by issues such as information being too general to be useful, too limited to be useful, or advice being insufficiently tailored to personal needs [14]. In addition, design issues, such as an unclear navigation structure, an unclear or unattractive layout, and the lack of a search engine or clear search options may interfere with users' needs. In our experience, the technical issues per se do not seem to set the limits for quality; what does so are successful design and trustworthy contents that help and support in everyday life [34].

This study also highlights the importance to users of having questions answered when needed [35]. In a recent study of question and answer services in primary care, the ability to make contact regardless of time and place, and the possibility of formulating questions in an undisturbed manner were important to patients. Their motivation for use strongly depended on getting a quick response and that the response came from a medical specialist [13]. Patients with long-term health issues may also consider other people's experiences, provided through personal stories, question and answer forums, or chat room facilities, as particularly good sources of practical information [3,5,31,34]. Regarding life with diabetes, there are many issues that cannot be solved from only a medical perspective but that demand practical experience, preferably that of a number of people. In this study, users regarded being enabled to connect to peers as advantageous, e.g., for getting answers, advice and hints, and for helping others and learning from those who were more experienced. Both young users and parents highlighted finding age-matched peers, as it was often difficult to find peers with a particular long-term disease in their physical neighborhood. 
Some mentioned that it was of value that the portal targets needs and perspectives of different groups, such as younger children, adolescents of different ages, young adults with diabetes, as well as parents, school professionals, health professionals and significant others. Whereas it is challenging to try to make everyone feel "there is something in it for me", the results along with those from previous studies also suggest that a further developed online community may enhance such positive experiences [3,31,36]. A portal where different views and perspectives can be shared within a sense of social presence in a community would probably help to attract users [7,32]. As some children are living with more than one long-term health issue, some respondents in the study perceived a lack of information and services directed to them and their particular needs. This concerned factual information as well as the potential to connect with others with similar experiences.

Previous studies indicate that in order to attract users, a living site is needed regarding various interactive elements such as discussion forums, blogs, questions and answers, and recent updates [3,32,34]. It was also the case in this study that some users were concerned about perceived low activity in the online community and on the site. This may reflect the fact that today's users expect a living site with high activity levels, and also that the practitioners were not used to the new Web 2.0 technology [3,25]. The practitioners in the present study were merely passive observers of dialogues in the discussion forums. One may question this strategy, as the information sought by young users is not limited to the experience of peers. In a recent multinational study, receiving information at diagnosis, and having access to multiple sources of information later, have been associated to better outcomes from young patients' and parents' perspectives [36]. The most frequently used source were diabetes medical teams, which might have valuable information to add in online dialogues provided they communicate in "the right way"whatever that means [37].

Indeed, site editors and practitioners need to balance a number of aspects aiming at professional information and dialogues that meet users' needs. This requires teamwork in integrating communication skills with the medical competence of several professions in order to meet the challenge of serving different user groups and ages. Since few systems work unless the individual components are in agreement, practitioners need to learn more about electronic communication with young patients. When information is transferred in an online community where dialogues are possible, the concept of intergradation might be useful for a deeper understanding [38]. This concept was recently used in studies about information exchange between nurses and children, and it means merging gradually with one another, maintaining the integrity of all, through unbroken sequences of information exchange. After being interconnected, intergradation is based on (1) acting according to accepted procedure, (2) completeness, (3) interdependence, and (4) social intercourse [38]. Exchanging information is a complex activity; clearly on the Internet it is important for practitioners to act according to accepted procedure and maintain integrity.

A particularly important issue is how to enhance users' trust in online health information [15]. According to experienced adult patients, trustworthiness is established by being accurate, having no commercial links, not displaying advertisements, being authored or sponsored by a known trustworthy organization and, importantly, that the site is regularly updated [34]. In population-based user surveys in Sweden, the importance of practitioners strongly outweighs other sources such as books or family for information related to medical issues [16]. We believe that if practitioners, patients and parents all feel secure about the information and the site, this may enhance coherence and support successful 
disease management [21-23]. Importantly, when practitioners, on their part, can control the information, they might also be more comfortable about recommending the site to patients [25].

\subsection{Future Issues}

The focus has shifted from whether healthcare should make use of Web 2.0 in communicating with patients toward how to increase the usefulness of interactive health portals in daily life and attract returning users. More attention must be focused on the education of clinical practitioners and others involved in the management of childhood long-term diseases regarding the use of online resources for parents and patients [3,25,31]. For future development and maintenance of such services, a holistic approach has been suggested to promote self-care and proactive online collaborations between health care professionals and patients [12]. Involvement of practitioners, payers and patients throughout the development process may enhance the development of durable interventions that take patients' support needs and emotional and financial outcomes into account [12,39].

\subsection{Future Research}

There is a continuous need to improve the channels for dialogue and questions between patients and practitioners [14,35]. The design used in the present study does not capture the views or characteristics of non-users. For future design work, updated knowledge of both non-users' and users' perspectives regarding their information retrieval is needed. Strategies are required to increase the value of the exchange of information between users, including how to strengthen credibility [2]. The optimal role of practitioners in this interplay remains to be determined. Finally, both ethical as well as gender aspects regarding the use of Web 2.0 dialogue tools in medicine need more attention [2].

\subsection{Conclusion}

Young users express positive perceptions towards a tailored, open Web portal combining patient communities, practitioners' facts, and other selected services and resources. Such open access services seem to have great potential for supporting young patients with long-term disease and their significant others. The complexity of target groups and their needs constitute great challenges for the development of high quality health information, as well as opportunities resulting from the integration of different perspectives_-intergrading for confidence.

\section{Acknowledgements}

We thank the participating patients and parents. This study was supported by the Linköping Centre for Life Science Technologies (LIST) at Linköping University, Sweden.

\section{References}

1. Eysenbach, G. Medicine 2.0: Social networking, collaboration, participation, apomediation, and openness. J. Med. Internet Res. 2008, 10, doi:10.2196/jmir.1030. 
2. Eysenbach, G.; Powell, J.; Englesakis, M.; Rizo, C.; Stern, A. Health related virtual communities and electronic support groups: Systematic review of the effects of online peer to peer interactions. BMJ 2004, 328, doi: 10.1136/bmj.328.7449.1166.

3. Nordfeldt, S.; Hanberger, L.; Bertero, C. Patient and parent views on a Web 2.0 Diabetes Portal—The management tool, the generator, and the gatekeeper: Qualitative study. J. Med. Internet Res. 2010, 12, doi:10.2196/jmir.1267.

4. Ravert, R.D.; Hancock, M.D.; Ingersoll, G.M. Online forum messages posted by adolescents with type 1 diabetes. Diabetes Educ. 2004, 30, 827-834.

5. Flicker, S.; Goldberg, E.; Read, S.; Veinot, T.; McClelland, A.; Saulnier, P.; Skinner, H. HIV-positive youth's perspectives on the Internet and e-health. J. Med. Internet Res. 2004, 6, doi:10.2196/jmir.6.3.e32.

6. Flicker, S.; Haans, D.; Skinner, H. Ethical dilemmas in research on Internet communities. Qual. Health Res. 2004, 14, 124-134.

7. Wasko, M.; Faraj, S. "It is what one does": Why people participate and help others in electronic communities of practice. J. Strateg. Inf. Syst. 2000, 9, 155-173.

8. van Uden-Kraan, C.F.; Drossaert, C.H.; Taal, E.; Shaw, B.R.; Seydel, E.R.; van de Laar, M.A. Empowering processes and outcomes of participation in online support groups for patients with breast cancer, arthritis or fibromyalgia. Qual. Health Res. 2008, 18, 405-417.

9. Elwell, L.; Grogan, S.; Coulson, N. Adolescents living with cancer: The role of computer-mediated support groups. J. Health Psychol. 2011, 16, 236-248.

10. Verhoeven, F.; van Gemert-Pijnen, L.; Dijkstra, K.; Nijland, N.; Seydel, E.; Steehouder, M. The contribution of teleconsultation and videoconferencing to diabetes care: A systematic literature review. J. Med. Internet Res. 2007, 9, doi:10.2196/jmir.9.5.e37.

11. Kaufman, N. Internet and information technology use in treatment of diabetes. Int. J. Clin. Pract. 2010, 166, 41-46.

12. Verhoeven, F.; Tanja-Dijkstra, K.; Nijland, N.; Eysenbach, G.; van Gemert-Pijnen, L. Asynchronous and synchronous teleconsultation for diabetes care: A systematic literature review. J. Diabetes Sci. Technol. 2010, 4, 666-684.

13. Nijland, N.; van Gemert-Pijnen, J.E.; Kelders, S.M.; Brandenburg, B.J.; Seydel, E.R. Evaluation of the use of an "ask-the-expert" e-consultation service for support on health-related requests. Stud. Health Technol. Inform. 2010, 160, 821-825.

14. Nijland, N.; van Gemert-Pijnen, J.; Boer, H.; Steehouder, M.F.; Seydel, E.R. Evaluation of internet-based technology for supporting self-care: Problems encountered by patients and caregivers when using self-care applications. J. Med. Internet Res. 2008, 10, doi:10.2196/jmir.9573.

15. Lampe, K.; Doupi, P.; van den Hoven, M.J. Internet health resources: From quality to trust. Methods Inf. Med. 2003, 42, 134-142.

16. Findahl, O. Svenskarna Och Internet 2010 (in Swedish); World Internet Institute: Stockholm, Sweden, 2010.

17. Povlsen, L. How can we adapt education for children across different countries? Horm. Res. 2002, $57,72-74$.

18. Plougmann, S.; Hejlesen, O.K.; Cavan, D.A. DiasNet-A diabetes advisory system for communication and education via the internet. Int. J. Med. Inf. 2001, 64, 319-330. 
19. Cadario, F.; Binotti, M.; Brustia, M.; Mercandino, F.; Moreno, G.; Esposito, S.; Baldelli, R.; Bona, G. Telecare for teenagers with type 1 diabetes: A trial. Minerva Pediatr. 2007, 59, 299-305.

20. Nordfeldt, S.; Johansson, C.; Carlsson, E.; Hammersjo, J.A. Use of the Internet to search for information in type 1 diabetes children and adolescents: A cross-sectional study. Technol. Health Care 2005, 13, 67-74.

21. Brink, S.J.; Miller, M.; Moltz, K.C. Education and multidisciplinary team care concepts for pediatric and adolescent diabetes mellitus. J. Pediatr. Endocrinol. Metab. 2002, 15, 1113-1130.

22. Ludvigsson, J.; Bolli, G.B. Intensive insulin treatment in diabetic children. Diabetes Nutr. Metab. 2001, 14, 292-304.

23. Hanberger, L.; Ludvigsson, J.; Nordfeldt, S. Quality of care from the patient's perspective in pediatric diabetes care. Diabetes Res. Clin. Pract. 2006, 72, 197-205.

24. Wikblad, K.F. Patient perspectives of diabetes care and education. J. Adv. Nurs. 1991, 16, 837-844.

25. Nordqvist, C.; Hanberger, L.; Timpka, T.; Nordfeldt, S. Health professionals' attitudes towards using a Web 2.0 portal for child and adolescent diabetes care: Qualitative study. J. Med. Internet Res. 2009, 11, doi:10.2196/jmir.1152.

26. Nordfeldt, S.; Ludvigsson, J. Adverse events in intensively treated children and adolescents with type 1 diabetes. Acta Paediatr. 1999, 88, 1184-1193.

27. Hanberger, L. Quality of Care in Children and Adolescents with Type 1 Diabetes: Patients' and Healthcare Professionals' Perspectives; Linköping University Electronic Press: Linköping, Sweden, 2010. Available online: http://urn.kb.se/resolve?urn=urn:nbn:se:liu:diva-59336 (accessed on 2 May 2012).

28. Timpka, T.; Eriksson, H.; Ludvigsson, J.; Ekberg, J.; Nordfeldt, S.; Hanberger, L. Web 2.0 systems supporting childhood chronic disease management: A pattern language representation of a general architecture. BMC Med. Inform. Decis. Mak. 2008, 8, 54.

29. Mayring, P. Qualitative content analysis. Forum: Qualitative Social Research 2008. Available online: http://www.qualitative-research.net/index.php/fqs/article/view/1089/2385 (accessed on 2 May 2012).

30. Krippendorff, K. Content Analysis. In An Introduction to Its Methodology, 2nd ed.; Sage Publication, Inc.: Thousand Oaks, CA, USA, 2004.

31. Bartlett, Y.K.; Coulson, N.S. An investigation into the empowerment effects of using online support groups and how this affects health professional/patient communication. Patient Educ. Couns. 2011, 83, 113-119.

32. Richardson, C.R.; Buis, L.R.; Janney, A.W.; Goodrich, D.E.; Sen, A.; Hess, M.L.; Mehari, K.S.; Fortlage, L.A.; Resnick, P.J.; Zikmund-Fisher, B.J.; Strecher, V.J.; Piette, J.D. An online community improves adherence in an internet-mediated walking program. Part 1: Results of a randomized controlled trial. J. Med. Internet Res. 2010, 12, doi:10.2196/jmir.1338.

33. Eysenbach, G. The law of attrition. J. Med. Internet Res. 2005, 7, doi:10.2196/jmir.7.1.e11.

34. Kerr, C.; Murray, E.; Stevenson, F.; Gore, C.; Nazareth, I. Internet interventions for long-term conditions: Patient and caregiver quality criteria. J. Med. Internet Res. 2006, 8, doi:10.2196/jmir.8.3.e13. 
35. Umefjord, G.; Sandstrom, H.; Malker, H.; Petersson, G. Medical text-based consultations on the Internet: A 4-year study. Int. J. Med. Inform. 2008, 77, 114-121.

36. Peyrot, M. The DAWN Youth WebTalk Study: Methods, findings, and implications. Pediatr. Diabetes 2009, 10, 37-45.

37. Martenson, E.K.; Fagerskiold, A.M.; Bertero, C.M. Observations of health-care professionals sharing and contributing responsibility in paediatric caring situations. Int. J. Nurs. Pract. 2009, 15, 185-190.

38. Martenson, E.K.; Fagerskiold, A.M.; Runeson, I.V.; Bertero, C.M. The ethical demand in nursing: A scandinavian perspective. Nurs. Sci. Q. 2009, 22, 281-288.

39. Pagliari, C. Design and evaluation in eHealth: Challenges and implications for an interdisciplinary field. J. Med. Internet Res. 2007, 9, doi:10.2196/jmir.9.2.e15.

(C) 2012 by the authors; licensee MDPI, Basel, Switzerland. This article is an open access article distributed under the terms and conditions of the Creative Commons Attribution license (http://creativecommons.org/licenses/by/3.0/). 